\title{
Synthesis and Crystal Structure of 1-2 Diphenyl ethylenediammonium Chloride
}

\author{
Sami Zouari,* Fatma Zouari,**† Nassira Chniba-Boudjada, *** and Pierre BordeT**** \\ *Institut des régions arides, 4119 Médenine, Tunisia \\ **Laboratoire des Sciences des Matériaux et d'Environnement, Faculté des Sciences de Sfax, \\ BP 802, 3018, Sfax, Tunisia \\ ***Laboratoire de cristallographie CNRS. BP 166. 38042 Grenoble cedex 9, France
}

\begin{abstract}
The salt 1-2 diphenyl ethylenediammonium chloride crystallizes at room temperature in the monoclinic system with polar space group $P 2_{1}$; the unit-cell dimensions are: $a=8.720(2), b=6.243(2), c=13.972(5) \AA, \beta=106.67(3)^{\circ}$ with $Z=2$. The structure consists of $\left[\mathrm{C}_{14} \mathrm{H}_{18} \mathrm{~N}_{2}\right]^{2+}$ cations and isolated chlorine anions. These entities are linked together through $\mathrm{N}-\mathrm{H} \cdots \mathrm{Cl}$ hydrogen bonds, forming a three-dimentional network.
\end{abstract}

(Received March 10, 2008; Accepted July 14, 2008; Published on web September 19, 2008)

The research of organic polar crystals is very interesting for quadratic non-linear optical phenomena, which is presently oriented to organic aromatic cations containing $\pi$-electrons systems asymmetrized by electron donor and/or accepted substitudes. ${ }^{1-3}$ Research has also been devoted to ionic hostmatrices that may increase the packing cohesion built up through ionic, hydrogen bonding and van der Wals interactions. Taking these considerations into account, we report on the chemical preparation and the crystal structure of 1-2 diphenyl ethylenediammonium chloride.

Crystals were obtained by dissolving in a concentrated $\mathrm{HCl}$ (36\%) solution of $\mathrm{C}_{14} \mathrm{H}_{18} \mathrm{~N}_{2}$ (molar ratio 1/2). The reaction occurred according to the following scheme: $\mathrm{C}_{14} \mathrm{~N}_{2} \mathrm{H}_{16}+2 \mathrm{HCl}$ in the presence of water. The resulting solution was then kept at room temperature. After several days of evaporation, parallelipipedic monocrystals appeared in the solution.

A single-crystal study was performed by using an EnrafNonius Kappa CCD diffractometer. The main crystal data and a summary of the parameters related to intensity data collection and structure refinement are reported in Table 1. The final atomic coordinates are given in Table 2. The crystal structure was solved by a direct method using the SHELXL 97 program, wich revealed the positions of all non-hydrogen atoms, and refined by a full matrix least-squares refinement. After introducing thermal-displacement parameters for the nonhydrogen atoms, the hydrogen atoms were localized and

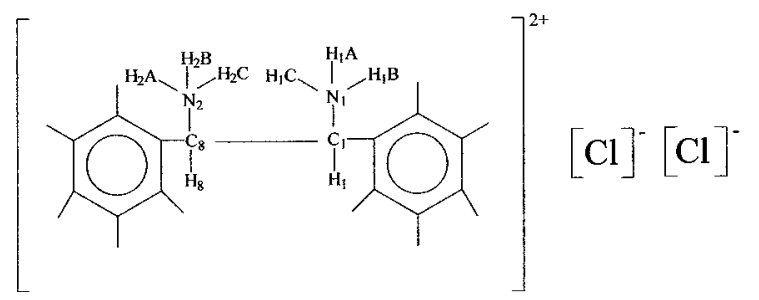

Fig. 1 Chemical structure of $\mathrm{C}_{14} \mathrm{H}_{182} \mathrm{~N}_{2} \mathrm{Cl}_{2}$.

† To whom correspondence should be addressed.

E-mail: fatmazouari2003@yahoo.fr optimized to restraint positions. Their thermal displacement contributions were isotropically introduced into the calculation and fixed. Corrections were applied for Lorentz and polarization effects and for absorptions. The final anisotropic full-matrix least squares resulted in a convergence of the $R$ factor at 0.0419 , $R w=0.1123$, and incorporating the weighting scheme $w=$ $1 /\left[\sigma^{2}\left(F_{0}^{2}\right)+(0.0539 P)^{2}+0.33 P\right]$, where $P=\left[\operatorname{Max}\left(F_{0}^{2}, 0\right)+\right.$ $\left.2 F_{\mathrm{c}}{ }^{2}\right] / 3$.

The atomic arrangement of the complex is depicted in Fig. 2. The structure of the title compound consisits of 1-2 diphenyl ethylenediammonium cations and isolated chlorine anions. The

Table 1 Crystal and experimental data

\begin{tabular}{ll}
\hline Compound & $\mathrm{C}_{14} \mathrm{H}_{18} \mathrm{~N}_{2} \mathrm{Cl}_{2}$ \\
Formula weight & 570.41 \\
Space group & $P 2_{1}$ \\
Temperature & $298 \mathrm{~K}$ \\
Cell constants & \\
$a$ & $8.720(2) \AA$ \\
$b$ & $6.243(2) \AA$ \\
$c$ & $13.972(5) \AA$ \\
$\beta$ & $106.67(3)^{\circ}$ \\
Cell volume & $724.67(3) \AA^{3}$ \\
Formula units/unit cell & 2 \\
$D_{\text {calc. }}$ & $1.300 \mathrm{~g} \mathrm{~cm}-3$ \\
Diffractometer/scan & Enraf-Nonius Kappa CCD \\
Radiation, graphite monochromator & $\mathrm{Ag} K_{\mathrm{a}}(\lambda=0.56087 \AA)$ \\
Max, crystal dimensions, mm & $0.12 \times 0.08 \times 0.09$ \\
$\mu_{\text {calc }}$ & $0.23 \mathrm{~mm}^{-1}$ \\
Unique reflections & 2581 \\
$2 \theta_{\max }$ & $40^{\circ}$ \\
No of parameters & 163 \\
Goodness-of-fit & 1.088 \\
Absorption correction & numerical \\
$R$ & 0.0419 \\
$(\Delta \rho)_{\text {max }}$ & $0.303 \mathrm{e} / \AA^{3}$ \\
$(\Delta \rho)_{\min }$ & $-0.404 \mathrm{e} / \AA^{3}$ \\
Refinement & full matrix \\
Computer programs & $\mathrm{SHELXL} 97$ \\
$C C D C$ & 679638 \\
\hline & \\
\hline &
\end{tabular}


Table 2 Atomic coordinates and temperature factors for $\mathrm{C}_{14} \mathrm{H}_{18} \mathrm{~N}_{2} \mathrm{Cl}_{2}$

\begin{tabular}{lllll}
\hline Atom & \multicolumn{1}{c}{$x$} & \multicolumn{1}{c}{$y$} & \multicolumn{1}{c}{$z$} & $U_{\text {eq }}$ \\
\hline C11 & $0.81191(8)$ & $-0.85832(17)$ & $0.49866(5)$ & $0.0370(2)$ \\
Cl2 & $0.36054(8)$ & $-0.86417(16)$ & $0.37827(5)$ & $0.0356(2)$ \\
N1 & $0.8161(3)$ & $-0.3680(6)$ & $0.45530(16)$ & $0.0310(5)$ \\
N2 & $0.4599(3)$ & $-0.3631(6)$ & $0.38800(17)$ & $0.0321(5)$ \\
C1 & $0.7215(4)$ & $-0.314(5)$ & $0.3502(2)$ & $0.0275(7)$ \\
C2 & $0.8204(3)$ & $-0.3732(7)$ & $0.28103(19)$ & $0.0306(6)$ \\
C3 & $0.8537(5)$ & $-0.2126(8)$ & $0.2198(3)$ & $0.0534(11)$ \\
C4 & $0.9512(6)$ & $-0.2630(9)$ & $0.1598(4)$ & $0.0567(15)$ \\
C5 & $1.0167(5)$ & $-0.4620(9)$ & $0.1623(3)$ & $0.0564(12)$ \\
C6 & $0.98835(4)$ & $-0.6177(8)$ & $0.2224(3)$ & $0.0480(10)$ \\
C7 & $0.8848(4)$ & $-0.5734(6)$ & $0.2817(3)$ & $0.0393(8)$ \\
C8 & $0.5613(3)$ & $-0.4342(5)$ & $0.3229(2)$ & $0.0279(7)$ \\
C9 & $0.4701(3)$ & $-0.4013(5)$ & $0.2138(2)$ & $0.0288(8)$ \\
C10 & $0.4560(4)$ & $-0.5685(7)$ & $0.1474(3)$ & $0.0409(9)$ \\
C11 & $0.3769(5)$ & $-0.5401(8)$ & $0.0470(3)$ & $0.0480(10)$ \\
C12 & $0.3128(4)$ & $-0.3448(10)$ & $0.0129(2)$ & $0.0499(10)$ \\
C13 & $0.3239(5)$ & $-0.1778(7)$ & $0.0779(3)$ & $0.0468(10)$ \\
C14 & $0.4038(4)$ & $-0.2044(7)$ & $0.1788(3)$ & $0.0394(8)$ \\
\hline
\end{tabular}

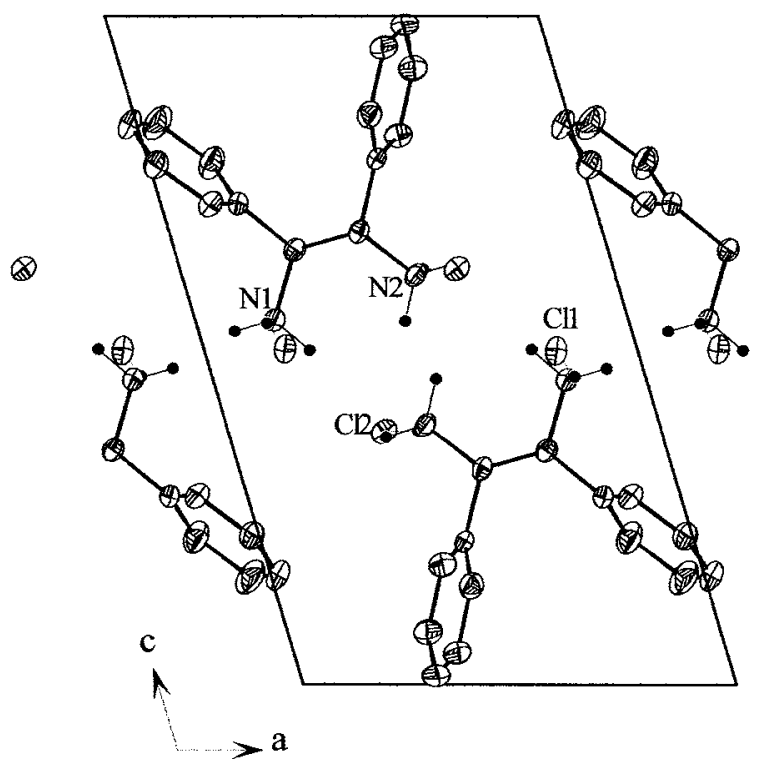

Fig. 2 Projection of the $\mathrm{C}_{14} \mathrm{H}_{182} \mathrm{~N}_{2} \mathrm{Cl}_{2}$ structure in the plane $(a, c)$.

most stable conical forms of 1-2 diphenyl ethylenediammonium cations indicate that the $\mathrm{N} 1$ and $\mathrm{N} 2$ atoms are protonated. In this compound, the cation, present as a dication, $\left[\mathrm{C}_{14} \mathrm{H}_{18} \mathrm{~N}_{2}\right]^{2+}$, has a cis configuration. Table 3 reports on the principal geometrical features of the $\left[\mathrm{C}_{14} \mathrm{H}_{18} \mathrm{~N}_{2}\right]^{2+}$ cations. The aliphatic bond lengths of C-N and C-C are in the range of 1.501(4) -
Table 3 Selected bond distances $(\AA)$ and angles $\left({ }^{\circ}\right)$

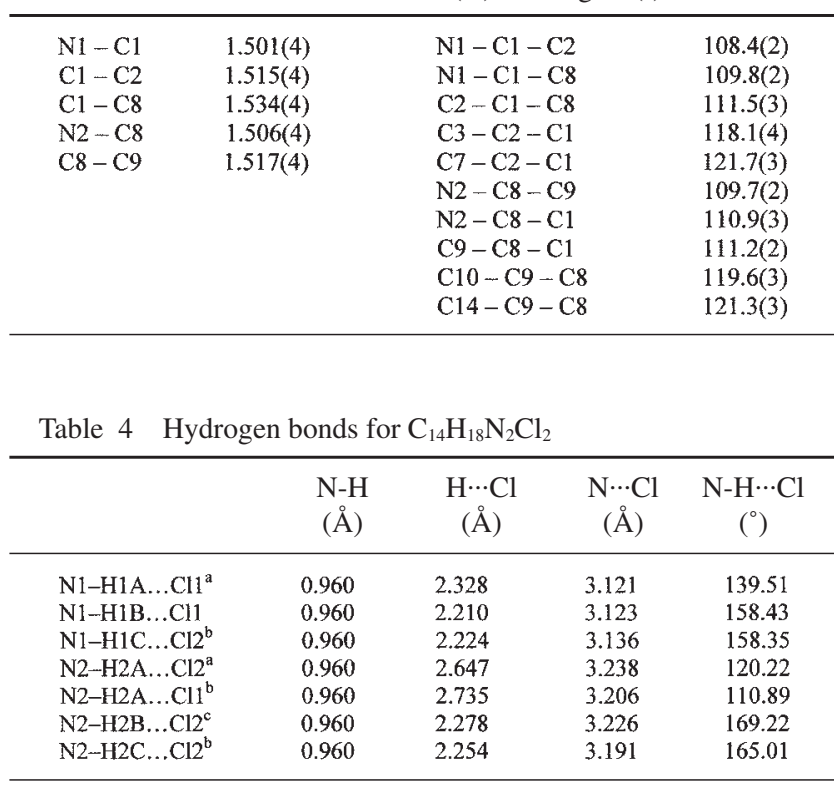

$\mathrm{a}:-x+2, y+0.5,-z+1 ; \mathrm{b}:-x+2, y+0.5,-z+1 ; \mathrm{c}:-x+2, y+0.5,-z+1$

$1.506(4) \AA$ and $1.515(4)-1.534(4) \AA$, respectively. The aromatic $\mathrm{C}-\mathrm{C}$ bond length varies from 1.364(7) to 1.401(6) $\AA$, which is in agreement with that found in related compounds. ${ }^{3,4}$ All of the hydrogen bonded to the nitrogen atoms participate in the formation of $\mathrm{N}-\mathrm{H} \cdots \mathrm{Cl}$ hydrogen bonding with distances of between 2.210 to $2.735 \AA$ (Table 4). Comparing their geometrical parammeters of the sum of the van der Waals radii of the hydrogen and acceptor atoms, ${ }^{5}$ they can be considered to be strong. The hydrogen bonds $(\mathrm{N}-\mathrm{H} \cdots \mathrm{Cl})$ give rise to a threedimensional network in the structure, which adds stability to this compound.

\section{References}

1. M. Abdi, A. Hadrich, and F. Zouari, Cryst. Res. Techno., 2008, 3, 314 .

2. N. Chaari, B. Hamdi, S. Chaabouni, and F. Zouari, Anal. Sci., 2007, 23, x1.

3. Z. Elaoud, S. Kamoun, T. Mhiri, F. Romain, and H. Burzlaff, J. Solid State Chem., 2000, 155, 298.

4. A. Lipka, Z. Anorg. Allg. Chem., 1980, 469, 218.

5. A. Bondi, J. Phys. Chem., 1964, 68, 441. 